\title{
Polycystic ovary syndrome (PCOS)
}

National Diabetes Information Clearinghouse (NDIC)

\section{Definitions}

Hormone

Defined by National Diabetes Information Clearinghouse (NDIC)

Diabetes

Defined by National Diabetes Information Clearinghouse (NDIC)

Insulin resistance

Defined by National Diabetes Information Clearinghouse (NDIC)

Obesity

Defined by National Diabetes Information Clearinghouse (NDIC)

\section{Source}

National Diabetes Information Clearinghouse (U.S.). (2009). The diabetes dictionary. [Bethesda, Md.]: U.S. Dept. of Health and Human Services, National Institutes of Health, National Institute of Diabetes and Digestive and Kidney Diseases, National Diabetes Information Clearinghouse.

A condition in which women have high levels of male hormones, increasing the risk of irregular or absent menstrual cycles, infertility, obesity, ovarian cysts, heart disease, and diabetes. PCOS is associated with insulin resistance. 